\title{
PRESENT TRENDS IN EARTH TERRESTRIAL SURFACES OBSERVATION FROM SPACE. EXPECTED PAYLOADS, DATA COOPERATION AND IMAGE ANALYSIS
}

\author{
Guy Flouzat ${ }^{1}$, Florence LAPORTERIE ${ }^{2}$, MARIE-Jose LEFEVRE-FonOllosA ${ }^{2}$ AND ERICK \\ LOPEZ-ORNELAS ${ }^{1}$ \\ ${ }^{1}$ Centre d'Etudes Spatiales de la Biosphère, BPI 2801, 31055 TOULOUSE CEDEX 4, ${ }^{2}$ Centre National \\ d'Etudes Spatiales, BPI , 31055 TOULOUSE CEDEX 4 \\ e-mail: guy.flouzat@cesbio.cnes.fr \\ (Accepted October 30, 2002)
}

\begin{abstract}
This paper presents remote sensing sensors: SPOT and LANDSAT systems are the most important providers of data in the 10-30 m spatial resolution range; NOAA (AVHRR radiometer) and SPOT4-5 (VEGETATION radiometer) provide coarse spatial resolution $(\sim 1 \mathrm{~km})$ but high frequency data. Microwave sensors are more recently available (radar on board of ERS1, ERS2, and RADARSAT). The principal methods of data cooperation to get benefits of these new technologies are described. Many combinations in the field of data fusion will contribute to enhance the perception of the terrestrial surfaces. A tentative review of this domain is proposed after a recall of a general definition. Finally, the present trends in image analysis for remote sensing coming from the evolution of the orbital sensors are developed.
\end{abstract}

Keywords: fusion, image analysis, payloads, remote sensing.

\section{INTRODUCTION}

The paper deals with the evolution of satellite technology and relevant data processing methods for remote sensing of terrestrial surfaces. The first part presents the current situation: SPOT and LANDSAT systems are the most important providers of data in the 10-30 $\mathrm{m}$ range; NOAA (AVHRR radiometer) and SPOT4-5 (VEGETATION radiometer) provide coarse spatial resolution $(\sim 1 \mathrm{~km})$ but high frequency data. Microwave sensors are more recently available (radar on board of ERS1, ERS2, and RADARSAT).

Then, the expected payloads for the next years are described with emphasis on sensors dedicated to the measurement and the knowledge of land use and terrestrial surfaces dynamics. The second part describes the principal methods of data cooperation to get benefits of these new technologies currently - or about to be - operational in space. Many combinations in the field of data fusion will contribute to enhance the perception of the terrestrial surfaces. A tentative review of this domain is proposed after a recall of a general definition. The third part deals with the present trends in the processing of remotely sensed images coming from the evolution of the orbital sensors. The current use of these data sets consists, first, in data classification yielding to land use maps, and secondly, in computing linear combination of reflectances at different wavelengths for environmental survey.

\section{PRESENT AND NEXT PAYLOADS}

The study of the "Earth System" from space corresponds to a major interest in the scientific, economic and political domains. The extreme complexity of this system as well as the diversity of the relationship between its compartments (atmosphere, oceans, and continents), justify the launch on orbit of different sensors dedicated to various applications. These observations, and the Earth monitoring, are done at several spatial and temporal scales and during long periods. Several kinds of Earth Observations programs exist. Some are dedicated to the study of the atmosphere and the oceans, others to the study of continents. In this paper, we focus on the latter and the main satellite and sensors onboard are described in Table 1.

Since the launch of the first Earth Observation satellite in the Sixties (i.e.TIROS), space data have been largely used to study of the continents and the littoral environment. These data are delivered by LEO (Low Earth Orbit - orbit lower than $1000 \mathrm{~km}$ ) satellites. Satellites are used in the civil field for scientific research, agriculture, regional planning or major risks. This work is carried out at various scales: global, regional, national or local. 
Table 1. Land use and terrestrial surface dynamics operational sensors.

\begin{tabular}{|c|c|c|c|c|c|c|}
\hline $\begin{array}{l}\text { SATELLITE } \\
\text { NAME }\end{array}$ & SOURCE & LAUNCH & SENSOR & MODES & $\begin{array}{c}\text { No. of } \\
\text { Channels }\end{array}$ & $\begin{array}{c}\text { RESOLUTION } \\
\text { (meter) }\end{array}$ \\
\hline \multirow[t]{3}{*}{ Landsat-5 } & \multirow[t]{3}{*}{$\overline{U S}$} & \multirow[t]{3}{*}{1984} & MSS & Multispectral & 4 & 82 \\
\hline & & & \multirow[t]{2}{*}{ TM } & Multispectral & 6 & 30 \\
\hline & & & & Multispectral & 1 & 120 \\
\hline \multirow{2}{*}{ SPOT-2 } & \multirow{2}{*}{ France } & \multirow[t]{2}{*}{1990} & \multirow[t]{2}{*}{ HRV } & Multispectral & 3 & 20 \\
\hline & & & & Panchromatic & 1 & 10 \\
\hline \multirow[t]{2}{*}{ IRS-1B } & \multirow[t]{2}{*}{ India } & \multirow[t]{2}{*}{1991} & LISS-I & Multispectral & 4 & 72.5 \\
\hline & & & LISS-II & Multispectral & 4 & 36,25 \\
\hline \multirow[t]{2}{*}{ ERS-1 } & \multirow[t]{2}{*}{ ESA } & \multirow[t]{2}{*}{1991} & AMI & Radar & 1 & 26 \\
\hline & & & ATSR & Multispectral & 4 & 1000 \\
\hline \multirow[t]{2}{*}{ RESURS-O1-3 } & \multirow[t]{2}{*}{ Russia } & \multirow[t]{2}{*}{1994} & MSU-SK & Multispectral & 4 & 170 \\
\hline & & & & Panchromatic & 1 & 600 \\
\hline NOAA-14 & US & 1994 & AVHRR & Multispectral & 5 & 1100 \\
\hline IRS-1C & India & 1995 & WiFS & Multispectral & 2 & 188 \\
\hline & & & LISS-III & Multispectral & 3 & 23 \\
\hline & & & & & 1 & 70 \\
\hline & & & Pan & Panchromatic & 1 & 5,8 \\
\hline ERS-2 & ESA & 1995 & AMI & Radar & 1 & 26 \\
\hline & & & ATSR & Multispectral & 4 & 1000 \\
\hline RADARSAT & Canada & 1995 & SAR & Radar & 1 & $9-100$ \\
\hline $\begin{array}{l}\text { ORBVIEW-2 } \\
\text { (SeaStar) }\end{array}$ & US/Orbimage & 1997 & SeaWiFS & Multispectral & 8 & 1,30 \\
\hline IRS-1D & India & 1997 & WiFS & Multispectral & 2 & 188 \\
\hline & & & LISS-III & Multispectral & 3 & 23 \\
\hline & & & & & 1 & 70 \\
\hline & & & Pan & Panchromatic & 1 & 5,8 \\
\hline SPOT-4 & France & 1998 & Végétation-1 & Multispectral & 4 & 1150 \\
\hline & & & HRVIR & Panchromatic & 1 & 10 \\
\hline & & & & Multispectral & 4 & 20 \\
\hline $\begin{array}{l}\text { NOAA-15 } \\
\text { (NOAA-K) }\end{array}$ & US & 1998 & AVHRR & Multispectral & 5 & 1100 \\
\hline Landsat-7 & US & 1999 & ETM+ & Multispectral & 6 & 30 \\
\hline & & & & & 1 & 60 \\
\hline & & & & Panchromatic & 1 & 15 \\
\hline $\begin{array}{c}\text { IRS-P4 } \\
\text { (Oceansat) }\end{array}$ & India & 1999 & OCM & Multispectral & 8 & 360 \\
\hline IKONOS & Space Imaging & 1999 & IKONOS & Multispectral & 4 & 4 \\
\hline & & & & Panchromatic & 1 & 1 \\
\hline CBERS-1 & China/Brazil & 1999 & $\mathrm{CCD}$ & Multispectral & 5 & 20 \\
\hline & & & IRMSS & Multispectral & 3 & 80 \\
\hline & & & & & 1 & 160 \\
\hline & & & WFI & Multispectral & 2 & 260 \\
\hline TERRA & US & 1999 & ASTER & Multispectral & 14 & $15-30-90$ \\
\hline (EOS AM-1) & & & MISR & Multispectral & 4 & 275 \\
\hline & & & MODIS & Multispectral & 36 & $250-500-1000$ \\
\hline NOAA-L & US & 2000 & AVHRR & Multispectral & 5 & 1100 \\
\hline EO-1 & US & 1999 & Hyperion & Hyperspectral & 220 & 30 \\
\hline & & & ALI & Panchromatic & 1 & 10 \\
\hline & & & & Multispectral & 9 & 30 \\
\hline & & & LAC & Hyperspectral & 256 & 250 \\
\hline EROS-A1 & ImageSat Int. & 2000 & EROS-A1 & Panchromatic & 1 & 1,5 \\
\hline Quickbird & DigitalGlobe & 2001 & Quickbird & Multispectral & 4 & 2.44 \\
\hline & & & & Panchromatic & 1 & 0,61 \\
\hline PROBA & ESA & 2001 & CHRIS & Hyperspectral & 62 & 50 \\
\hline $\begin{array}{c}\text { AQUA } \\
(\text { EOS PM-1) }\end{array}$ & US & 2002 & MODIS & Hyperspectral & 36 & $250-1000$ \\
\hline SPOT-5 & France & 2002 & Végétation-2 & Multispectral & 4 & 1150 \\
\hline & & & $\mathrm{HRG}$ & Panchromatic & 1 & 2,5 \\
\hline & & & & & 1 & 5 \\
\hline & & & & Multispectral & 4 & 10 \\
\hline & & & HRS & Panchromatic & $1 /$ stereo & $5 \times 10$ \\
\hline
\end{tabular}


Between 1972 and 1999, in the optical domain, two kind of complementary sensors are available. They both have a reduced number of spectral bands (maximum 10) comprised between about 0.5 and 1.8 $\mu \mathrm{m}$ and having a $0.2 \mu \mathrm{m}$ width:

- LS (Large Swath) instruments as AVHRR or VEGETATION (Fig. 1) are multispectral imaging devices and provide daily data about the biomass for example, with a spatial resolution of approximately $1 \mathrm{~km}$ and a swath (width of the acquired image) of more than $1000 \mathrm{~km}$.

- MS (Middle Swath) instruments as LANDSAT, SPOT or IRS are also multispectral imaging devices but are mainly used for cartography. They have an increasingly fine spatial resolution, for example $30 \mathrm{~m}$ from LANDSAT-TM to $20 \mathrm{~m}$ for SPOT 4 and $10 \mathrm{~m}$ for SPOT 5 (Fig. 2) combined with a swath of roughly $100 \mathrm{~km}$. Contrary to LS sensors, they have a coarse temporal frequency. They also have a panchromatic imaging device providing data at $15 \mathrm{~m}$ for LANDSAT-TM, $10 \mathrm{~m}$ for SPOT 4 and $2.5 \mathrm{~m}$ for SPOT 5.

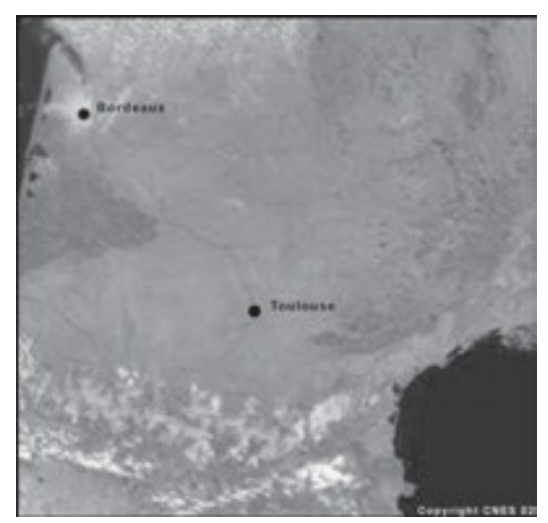

Fig. 1. Image from VEGETATION sensor on board SPOT5 covering the South West part of France.

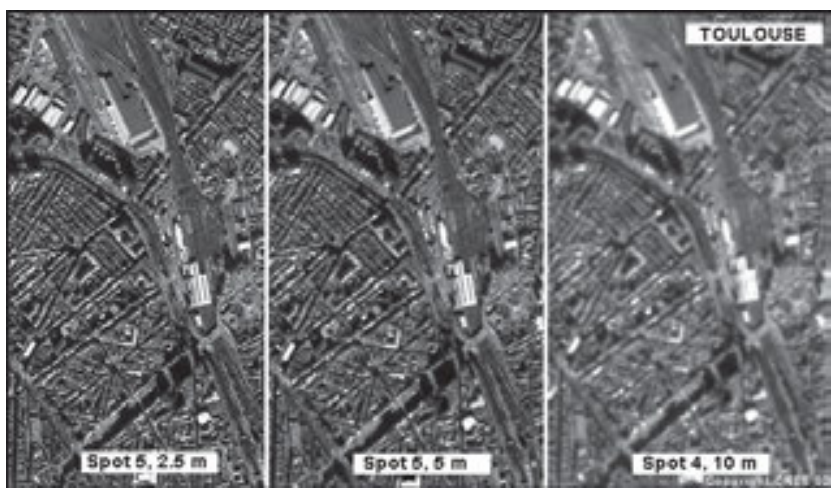

Fig. 2. Comparison of Spot 4 and Spot 5 images of Toulouse, France (panchromatic image at $2.5 \mathrm{~m}$ and $5.5 \mathrm{~m}$ for Spot 5 and $10 \mathrm{~m}$ for Spot 4 ).
Thus, all the available sensors provide several kinds of images:

1. First of all, for technical reasons, the more the spectral band is narrow, the coarser the spatial resolution is. So, some images have a large spectral band covering the entire visible band and sometimes part of the infrared one, and a high spatial resolution; they are called panchromatic images. Others have a mid spectral band and a mid resolution: one image corresponds to one colour. In this case, each sensor can acquire several images in few spectral bands and provides multi-spectral images, often in the red, the green, and the near-infra red range. MS and LS sensors provide these two kinds of image.

2. Secondly, a large swath is combined with a good temporal frequency of acquisition.

3. Finally, because of the limited size of a CDD camera, a good swath implies a poor spatial resolution.

Practically, MS sensors provide multi-spectral data with a spatial resolution comprised between $30 \mathrm{~m}$ and $2.44 \mathrm{~m}$ depending on the technology employed and panchromatic data with a spatial resolution of 2 to 4 times less. Then, the swath varies between about 100 $\mathrm{km}$ and $10 \mathrm{~km}$, respectively. Finally, their temporal frequency is at best one month. On the contrary, LS sensors provide multi-spectral data with a spatial resolution of $1 \mathrm{~km}$, a daily temporal frequency and a swath of about $1000 \mathrm{~km}$. In the future, the two principal classes of LS and MS sensors will continue to be programmed, at least until 2007. At the same time, a diversification of the payloads is noticed. It moves toward the three following directions (Fig. 3):

- LS sensors tend towards an improvement of their spatial resolution in a ratio 2 or 4 , with, in parallel, an increase in the number of spectral bands that become narrow $(\Delta \lambda=1$ to $10 \mathrm{~nm}$, i.e. Hyperspectral LS type). For examples, MODIS (1999) and LAC (1999) are characterized by an improvement of their spatial resolution $(1 \mathrm{~km}$ $>300 \mathrm{~m}$ ) and spectral (more than 30 bands). These new imaging devices are more particularly dedicated to the study of the environment and significantly improve the knowledge of the color of the oceans (phytoplancton, sedimentation, and pollution).

- The MS sensors move toward two different directions: the high spectral resolution or the high spatial resolution. 
- Indeed, for sensors with a high spectral resolution (i.e. Hyperspectral MS type), the narrowness of the spectral bands does not allow yet the simultaneous improvement of the resolution. One of the main technological difficulties is the storage and the transmission of a significant amount of data. HYPERION (2000) and CHRIS (2001) combine a spatial resolution of about $30 \mathrm{~m}$ with an important number of spectral bands (between 30 and 250). They are used for the study of agriculture, environment and the littoral.

- The sensors with High Resolution (i.e. HR type) represent a prioritary tendency. The gain in resolution is done to the detriment of the swath. Currently, one of the principal axes of $R \& T$ consists in increasing the swath without loss of spatial resolution. IKONOS (1999), EROS (2000), QUICKBIRD (2001) are examples of a new generation of sensors characterized by metric and submetric resolutions (Fig. 4).
PLEIADES - HR will be launch in 2006 with a resolution of $0.8 \mathrm{~m}$. These very accurate data are dedicated to regional planning or urban environment cartography.

Moreover, in all cases, improving the temporal frequency is performed via two kinds of innovations. On the one hand, the improvement of the platform agility will enable the system to acquire images of an area of interest, even if this area is not exactly beneath. Secondly, the use of constellations is a powerful means to improve the access time to the zones of interest (the system SPOT with 3 phased satellites allows a daily observation of all the Earth). Thus, the space systems of the $21^{\text {st }}$ century meet major needs requested by the users: a fine resolution in order to approach the aerial observation, a greater number of narrow spectral bands to improve the recognition, a strong repetitivity in order to be able to ensure the monitoring of certain events. Nevertheless, it is not currently feasible, to combine these various performances on a single sensor.

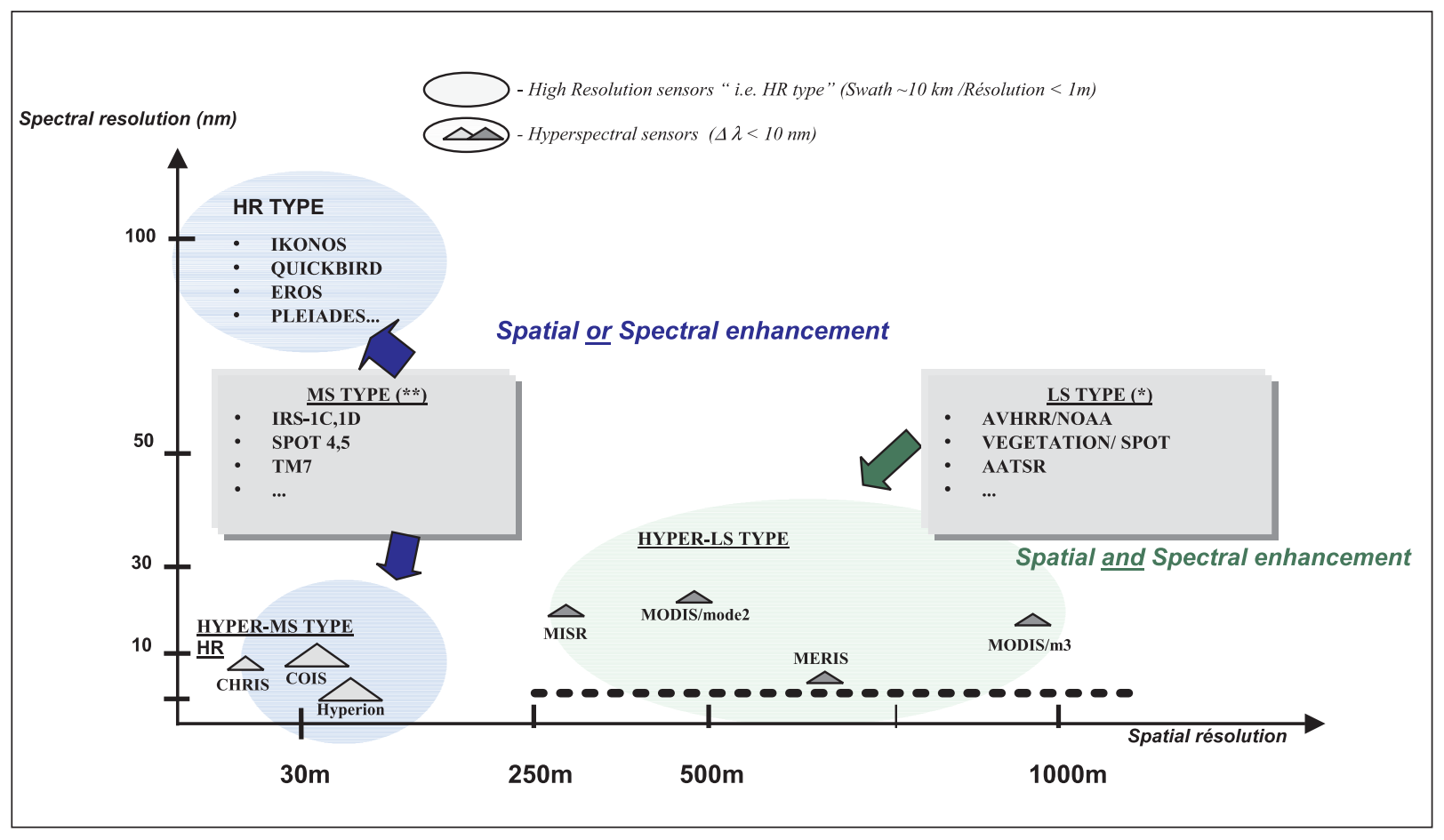

Fig. 3. Evolution of the main payloads (only in optic domain). (*) Large Swath sensors i.e. LS type) (> 1000km / Resolution $\sim 1 \mathrm{~km})$, (**) Middle Swath sensors i.e. MS type ( 100km / Resolution : 10-30m). 


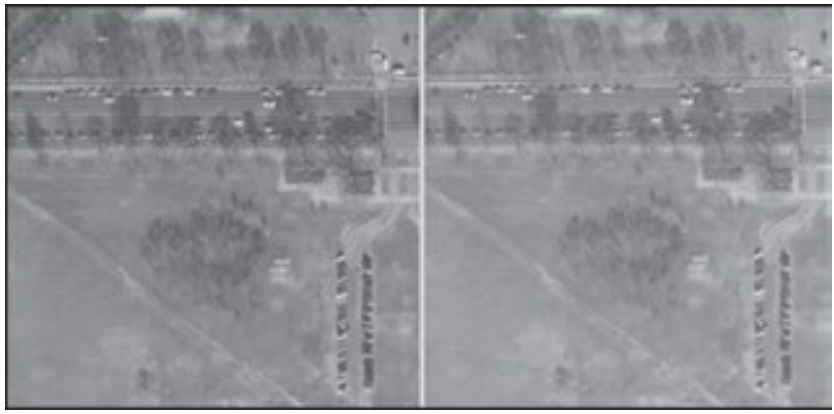

Fig. 4. Images of Washington D.C. at $0.60 \mathrm{~m}$ and 1.2 $m$ resolution (IKONOS satellite).

Then, innovative concepts enable the creation of a DTM (Digital Terrain Model) providing 3D maps. The SRTM instrument (Shuttle Radar Mapping Ground) provides a DTM with a vertical accuracy of $30 \mathrm{~m}$ over the whole planet; HRS (High Resolution Stereoscopy) on SPOT5 (Fig. 5) carries out also in a systematic way an accurate DTM (vertical accuracy 3-5 m); satellites such as IKONOS, EROS and QUICKBIRD get, but at request, a DTM more precise than the meter.

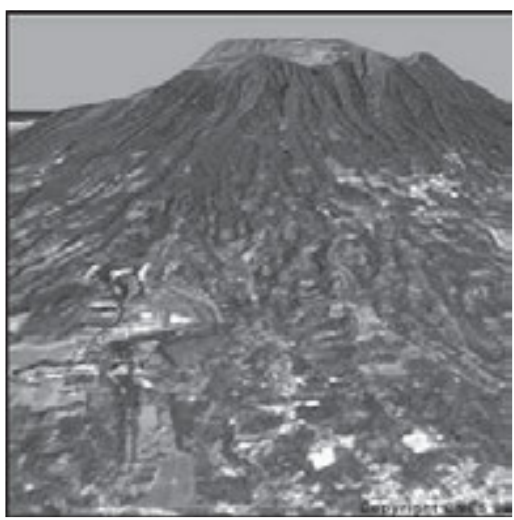

Fig. 5. 3D image reconstruction of the VESUBIO area using both HRG and HRS sensors on board SPOT5.

Finally, one of the most promising solutions could be a high-resolution geostationary observation. Indeed, this would authorize a quasi-permanent observation of the entire hemisphere located under the platform. A geostationnary MS sensor is already technically possible; it could carry out the monitoring of the hemisphere at a resolution of 10 or $30 \mathrm{~m}$ with a swath of several hundred kilometers. This type of instruments enables a high spectral resolution because it can adapt the time of integration of the acquisition, thus improving the level of brightness measured. Currently, our research axis is focused on the improvement of the spatial resolution of geostationary sensors in order to approach the meter. This cannot be done without a major technological jump that may consist in putting into orbit around the Earth a system composed of several large controlled telescopes (3 or 4). This technology, called Optical Opening Synthesis System, is already used on the ground in the field of astronomy. The final high-resolution image $(2 \mathrm{~m}$ approximately) is performed by the synthesis of the images acquired by the various telescopes.

In conclusion, we can note that the beginning of decade 2000 is characterized by a very great diversity of satellites placed, either in geostationary orbit, or in LEO orbit. They collect data of varied resolutions (from $25 \mathrm{~km}$ to $0.6 \mathrm{~m}$ ), in various spectral bands (mono, multi, and hyperspectral).

\section{MIXING THE DATA}

So, all the data acquired have complementary properties. For several applications, a good spatial resolution, a good spectral resolution (several images having narrow bands) and a good temporal frequency are necessary. Consequently, the only acquisition of images is not enough and further processing such as fusion are needed. When the spatial and spectral resolutions are important, we usually combine panchromatic and multi-spectral data. It is the most common fusion in remote sensing. When the temporal frequency and the spatial resolution are necessary, we combine MS multi-spectral with LS multi-spectral data. Of course, mixing every kind of images has a great interest, but the current techniques of image analysis often do not product good enough results. A lot of fusion methods exist. Hereafter, we focus on those methods dedicated to multi-resolution images. Such methods can be separated in three classes based on different theories: statistics, colorimetry and signal processing, respectively.

Three main processes are derived from statistics. First, the unmixing of heterogeneous pixels is performed as follow:

- A high-resolution image, for example coming from a MS sensor, is used to determine the location of objects in a studied area.

- Coarse resolution images coming from LS sensors are considered to be composed of heterogeneous pixels, mixing several themes underneath. Using the composition of the area determined on the high-resolution image, it is then possible to express the reflectance of a coarse pixel according to the unknown reflectance of each theme weighted by its surfaces.

- Having a temporal series of coarse resolution images enables the calculation, by linear regression, of the unknown reflectances of the various themes 
mixed in a coarse pixel. The result is not a temporal series of HR images: this method does not provide the geometrical repartition of the themes contained in coarse pixels, but only the set of reflectances at each date and for each pixel.

This method is often used to merge LS and MS images (Quarmby et al., 1992; Puyou-Lascassies et al., 1994; Faivre and Fisher, 1997; Zhukov et al., 1999; Cherchali et al., 2000; Minghelli et al. 2001).

The second method is to perform a PCA on all the data available. The principal components keep most of the information, especially the information about small elements, visible only on the highresolution image(s). This method is very simple, but this kind of mixing looses all the spectral information of the different images (Yesou et al., 1993; 1994; Chavez and Kwarteng, 1989).

The third method merges one panchromatic and one band of the multi-spectral data. The high-resolution image is degraded to the coarse resolution. Then one image is expressed according to the other one thanks to a linear regression. The coefficient of the regression is used at the high resolution and enables the calculation of a merged image showing high spatial and spectral resolutions (Tom, 1986; Price, 1987; Pavel and Sharma, 1996; Sharma and Pavel, 1996; Diemer and Hill 2000).

The colorimetric approach concerns essentially the fusion of a panchromatic and 3 MS multi-spectral images. The multi-spectral data are sampled to the size of the high-resolution image and coded from the RGB (Red-Green-Blue) to the IHS space (LefevreFonollosa and Cruchant, 1985; 1986; 1987; Cruchant and Lefevre-Fonollosa, 1990). Then, the resulting intensity image (I) is replaced by the panchromatic image. Finally, the inverse transform panchromatic image HS space to RGB space is performed. The three resulting images are considered as the merged product (Welch and Ehlers, 1987; Harris et al., 1990; Dwivedi et al. 2001). This method is very simple, but, as PCA, it raises the problem of the conservation of the spectral content of the merged images. Thus, many improvements have been proposed (Carper et al., 1990; De Bethune et al., 1997; 1998; Paradella et al., 1997; Shetselaar, 2001).

The different data can also be merged thanks to arithmetic combination. This is the easiest method, but the quality of the result greatly depends on the input data. A preliminary operation is to sample the coarse resolution image(s) to the size of the highresolution image(s). The images can then be mixed by addition (Chavez, 1986; Chavez and Bowell 1988), and / or subtraction and / or product (Filiberti et al., 1994; Zhang, 1999; Liu and Moore, 1998; Liu, 2000). Some authors (Cliche et al., 1985; Pradines, 1986; Price, 1987) improved this kind of method.

Finally, three types of methods are derived from the signal processing theory. Many developments rely on the approach of Marr (1982) and correspond to a complete characterization of transitions. In this framework, the first kind of method is based on highpass filtering. The method consists in filtering a highresolution image using a high-pass filter and then to inject the extracted high frequencies in a coarse resolution image. Schowengert (1980) first developed this method. To take into account the spectral characteristics of the coarse resolution image, Chavez and Bowell (1988) proposed to limit the amount of high frequencies injected.

The second type of method is based on the wavelet transform (Mallat, 1989). A wavelet transform is carried out on the high spatial resolution image. The coarse resolution image resulting from the transform is then replaced by the coarse resolution sensor image. Finally, the inverse wavelet transform is applied. In fact, to avoid the problem posed by the spectral differences between images, this technique has been further refined. The principal groups working on wavelet data fusion in remote sensing are Ranchin and Wald (Ranchin, 1998; Ranchin and Wald, 2000), Nunez et al. (1998a; 1998b; 1999a; 1999b) and Yocky (1996). Yet, other works exist (Proenca and Flouzat, 1991; Proenca, 1992; Garguet-Duport et al., 1996; Zhou et al., 1998; Scheunders and De Backer, 2001).

The last kind of method is based on pyramid algorithms and provides a lot of different processes. They have been studied by both Burt and Adelson (1983) and Crowley and Stern (1984), who developed the representation of images through Laplacian pyramids. As far as fusion is concerned, a highresolution image is decomposed by a pyramid algorithm to decrease its spatial resolution. During the process, several images are created, some representing the small elements of the images, others being a coarser resolution version of the initial image. Then, the inverse transform is performed with the coarse resolution sensor image and the necessary small elements. This kind of process can be used to merge every kind of multi-resolution images, either panchromatic and MS multispectral (Aiazzi et al., 1998; 1999) or MS multispectral and LS multispectral (Laporterie et al, 2000; 2001; Laporterie and Flouzat, 2002; Flouzat et al. 2001). 
To conclude, the main problems of remote sensing data fusion are:

- on the one hand, the difference in spectral content of the high and coarse spatial resolution images, especially during the fusion of MS panchromatic and MS multi-spectral images;

- on the other hand the huge resolution ratio, about 50 , during the fusion between multispectral MS and LS images.

The easiest methods, such as those based on highpass filtering, IHS transform, PCA and arithmetic combinations provide a poor respect of the spectral content of the coarse resolution image(s). The other methods are more complicated to implement and use. Consequently, the choice of a fusion process greatly depends on the use of the merged product as well as on the types of observed surfaces.

\section{TRENDS IN THE PROCESSING OF REMOTELY SENSED IMAGES}

The apparition of HR MS sensor together with the improvement of the temporal frequency of acquisition and the growing use of fusion lead to an increase of the amount of data to be processed. Furthermore, the improvement of the spatial resolution requires a renew of the traditionally used image processing methods. Methods, currently applied on decametric data, are based on classification and on the calculation of indices to model landscapes. Unfortunately, this kind of characterization is not suitable when metric resolutions are concerned.

\section{Current data use: classification, indices, modelisation and forcing}

Firstly, the classification process consists in splitting an image into several classes of pixels. Every pixel of one class is closer (according to some criterion) to all other pixels of the same class than to the pixels in any other class. Thus, it is to calculate the best partition in the spectral band space $\left(E_{k}\right)$. Let $\mathrm{C}$ be the set of classes: $C=\left\{c_{1}, \ldots, c_{i}\right\}$. The partition is searched in the $E_{k}$ space having $k$ dimension, each corresponding to a spectral band. A metric is defined (i.e., a distance in $E_{k}$; for example the Euclidean distance). Then a training enables the calculation of the $i$ centers of the $i$ classes. Classification methods are the most frequently used in remote sensing to produce land use maps. Examples can be found in Irons et al., 1985; Lillesand and Kiefer, 1987; Benediktsson and Swain, 1992; Bischof et al., 1992; Heermann and Khazenie, 1992; Foody et al., 1995.
When the point is to focus on specific properties of terrestrial surfaces, indices are used in remote sensing (Perry and Lautenschlager, 1984; Huete, 1988; Mougin et al., 1995; Verstraete and Pinty, 1996). For example, the NDVI (Normalized Difference Vegetation Index $)$, defined as NDVI $=\left(\rho_{\text {NIR }}-\rho_{\text {RED }}\right) /\left(\rho_{\text {NIR }}+\rho_{\text {RED }}\right)$ (where $\rho_{\mathrm{NIR}}$ and $\rho_{\mathrm{RED}}$ are respectively the reflectance in the Near InfraRed and Red domains) is the mostly used index describing the chlorophylian behavior of the vegetation. However, two situations happen:

- with MS decametric spatial resolution data, a pixel represents a single kind of vegetation characterized by the NDVI. However, a few images are acquired during the year, and an accurate study of the vegetation is not possible.

- with LS high temporal frequency data, the number of observations per year is sufficient to characterize the evolution of the vegetation all the year long. However, the kilometric resolution results in mixed pixels, each carrying information about several types of vegetation.

That is why competitive fusion processes are crucial.

Another typical approach is the integration of remotely sensed data in the modeling of biosphere processes (Goward and Dye, 1997; Cihlar et al., 1997). In a first approach, images are considered as a set of physical measurements and are the input data for models. They enable the spatial extension of models. Another common approach is this one: models provide some characteristics such as reflectance and temperature that can be also measured from space. Remotely sensed images can be compared with the output of the models, and the deviation is used as a feedback engine to improve the model parameters.

\section{Most important trends}

However, the arrival of very high spatial resolution images enables the perception of a new range of objects. For example, in Fig. 4, a lot of lowsize objects are visible: vehicles, tree stems, marks on the roads. Furthermore, the $0.60 \mathrm{~m}$ resolution shows a vision improvement of these objects when compared to the $1.20 \mathrm{~m}$ resolution case. This kind of perception highlights the surface characteristics, morphologies and objects organization. In front of this situation, the current methods explained in the last paragraph are no longer efficient; news methods begin to be developed but very few results are already available. Trends of the new processes are described hereafter.

1. Objects characterization and interaction with 
geographical information systems (GIS).

New objects are now accessible from space and can be integrated into GIS and used to improve the modeling of spatial processes. Consequently, the description of terrestrial surfaces and their evolution should be improved. However, as shown in Fig. 4, the increase of the spatial resolution complicates segmentation processes that should be improved by self-adapting prototypes and interaction with GIS. Finally, coupling geographical information interpretation and segmented structure may leads to a better comprehension of images.

2. Researches coupling high spatial resolution and high temporal frequency data.

As seen in section IV, data fusion hardly never combines high spatial resolution and high temporal frequency data. For example, Fig. 1 shows an area that can be observed every day with large field sensors (in clear sky conditions). Using both unmixing processes and multiresolution decompositions to combine temporal series of LS images with few MS images should provide MS temporal series and should be a good compromise for spatio temporal approach. Another important coupling to develop is the synergy between optical and radar sensors, within and outside the scope of data fusion.

3. Volume description and morphological characterization of surfaces.

Some of the new satellites, such as SPOT5, own two HR sensors designed to provide accurate 3D images. This offers new opportunities for the characterization of the vegetation morphology and texture and enables the improvement of biophysics description. Consequently, on the one hand classifications may use height characteristics, and on the other hand the use of $3 \mathrm{D}$ will become an important tool to estimate landscape transformations.

Then, the domain of water resources is very important, and 3D can provide information on existing interactions between geometry and flow. Fig. 5 is a $3 \mathrm{D}$ reconstruction that uses SPOT5 images to represent this principle of description: at every points, the geometry (slope, azimuth, ...) and the radiometry (reflected part of the incident radiation) are available.

Finally, the geometry and the morphology of the spatial distribution of the vegetation layers are determining factors for hydrological processes. The statistical characterization and the identification of land use are insufficient and a specific quantification is required. This is fundamental because the hydrological processes depend on exchanges between the ground and the atmosphere as well as on the processes of spatial distribution of water flows in the watershed. This quantification is the only way to improve the description of these interactions in hydrological models.

\section{CONCLUSION}

In the next decade, the Earth Observation technology is facing many challenges: sensor technology improvement, data fusion and data processing and precision surveying. Remote sensing applications are complex, requiring data at global, regional and local scales, and at several temporal frequencies. In this framework, an important goal is to continue the improvement of the sensor technology in order to meet efficiently the users' needs. Indeed, despite the variety of satellites in orbit, there are still lacks: processing methods must be adapted to the payload diversity to provide high-quality "end products" in two ways. The first one concerns data fusion enhancement, and the second one is the idea of feedback processes between high-resolution image analysis and geographic information. Furthermore, mixing high resolution and high temporal frequency data can overcome, in some cases, the spatio temporal limits of satellites. This way, we underline the potential interest of high resolution (temporal and spatial) surveys for environmental monitoring. This leads to the concept of precision surveying adapted to spatial dynamics assessment at local scale needed in the cases where populations are concerned. This concept has its place in the frame of global change research due to its spatio temporal zooming capabilities at every point of the Earth.

\section{REFERENCES}

Aiazzi B, Alparone L, Baronti S, Carla R (1998). An assessment of pyramid-based multisensor image data fusion. In: Proceeding SPIE Europto, Image and signal processing for remote sensing, 237-47.

Aiazzi B, Alparone L, Argenti F, Baronti S (1999). Wavelet and pyramid techniques for multisensor data fusion: a performance comparison varying with scale ratios. In: Proceedings SPIE Europto, Image and signal processing for remote sensing V, 251-62.

Benediktsson JA, Swain PH (1992). Consensus theoretic classification methods. IEEE Transactions on Systems, Man \& Cybernetics 22(4):688-704.

Bischof H, Schneider W, Pinz AJ (1992). Multispectral classification of Landsat images using neural networks. IEEE Transactions on Geoscience and Remote Sensing 30(3):482-90. 
Burt PJ, Adelson EH (1983). The Laplacian pyramid as a compact image code. IEEE Trans on Comm 31(4):53240, 1984.

Carper W, Lillesand T, Kiefer R (1990). The use of Intensity-Hue-Saturation transformations for merging SPOT Panchromatic and multispectral image data. Photogram Eng and Rem Sens 56(4):459-67.

Chavez P (1986). Digital merging of Landsat TM and digitalized NHAD data for 1: 24,000-scale image mapping. Photogram Eng and Rem Sens 52(10):163746.

Chavez P, Bowell J (1988). Comparison of the spectral information content of Landsat Thematic Mapper and SPOT for three different sites in the Phoenix Arizona Region. Photogram Eng and Rem Sens 54(12):1699708.

Chavez P, Kwarteng A (1989). Extracting spectral contrast in Landsat Thematic Mapper image data using selective Principal Component Analysis. Photogram Eng and Rem Sens 55(3):339-48.

Cherchali S, Amram O, Flouzat G (2000). Retrieval of temporal profiles of reflectances from simulated and real NOAA-AVHRR data over heterogeneous landscapes. Intern Journal of Rem Sens 21(4):753-75.

Cihlar J, Chen JM, Li Z (1997). Seasonal AVHRR Multichannel Data Sets and Products for Scaling up Biospheric Processes. Journal of Geophysical Research 102:29625-40.

Cliche G, Bonn F, Teillet P (1985). Integration of the SPOT panchromatic Channel into its multispectral mode for image sharpness enhancement. Photogrammetric engineering and remote sensing 51(3):311-6.

Crowley JL, Stern RM (1984). Fast computation of the difference of low pass transform. IEEE Trans Pattern Anal Mach Intell 6:212-22.

Cruchant H, Lefevre-Fonollosa M-J (1990). Utilisation des principes de la vision des couleurs en traitement d'images SPOT, pour l'aide à la photo-interprétation. Revue de photo-interprétation n¹990-3-4.

De Bethune S, Muller F, Binard M (1997). Adaptative intensity matching filters: a new tool for multiresolution data fusion. In: AGARD SSP Symposium on multisensor systems and data fusion for telecommunications, remotes sensing and radar, 28/1-28/15.

De Bethune S, Muller F, Donnay J (1998). Fusion of multispectral and panchromatic images by local mean and variance matching filtering techniques. In: Proceedings Fusion of earth data, Sophia Antipolis, 31-6.

Diemer C, Hill J (2000). A local correlation approach for the fusion of remote sensing data with different spatial resolutions. In: Proceedings Fusion of Earth Data, Sophia Antipolis, France,91-8.

Dwivedi R, Ramana K, Thammappa S, Singh A (2001). The utility of IRS-1C LISS-III and PAN-merged data for mapping salt-affected soils. Photogram Eng and Rem Sens 67(10):1167-75.
Faivre R, Fisher A (1997). Predicting crop reflectances using data observing mixed pixels. Journal of Agricultural, Biological and Environmental Statistics 2(1):87-107.

Filiberti D, Marsh S, Schowengerdt R (1994). Synthesis of imagery with high spatial and spectral resolution from multiple image sources. Optical engineering 33(8):25208.

Foody GM, McCulloch MB, Yates WB (1995). Classification of remotely sensed data by an artificial neural network: issues related to training data characteristics. Photogrammetric Engineering and Remote Sensing 61(4):391-401.

Flouzat G, Amram O, Laporterie F, Cherchali S (2001). Multiresolution analysis and reconstruction by a morphological pyramid in the remote sensing of terrestrial surfaces. Signal Processing 81(10):2171-85.

Garguet-Duport B, Girel J, Chassery J, Pautou G (1996). The use of multiresolution analysis and wavelets transform for merging SPOT Panchromatic and multispectral image data. Photogrammetric Engineering and Remote Sensing 62(9):1057-66.

Goward SN, Dye D (1997). Global biospheric monitoring with remote sensing. In: Gholtz HL, Nakane K, Shimoda H, eds. The use of remote sensing in modeling forest productivity. New York: Kluwer Academic.

Harris J, Murray R, Hirose T (1990). IHS Transform for the integration of radar imagery and other remotely sensed data. Photogrammetric Engineering and Remote Sensing 56(12):1631-41.

Heermann PD, Khazenie N (1992). Classification of multispectral remote sensing data using a backpropagation neural network. IEEE Transactions on Geoscience and Remote Sensing 30(1):81-8.

Huete AR (1988). A soil-adjusted vegetation index (SAVI). Remote Sens Environ 25:89-105.

Laporterie F, Amram O, Flouzat G, Pilich E, Gay M (2000). Data fusion thanks to an improved morphological pyramid approach: comparison loop on simulated images and application to SPOT 4 data. Juillet 2000, Paper int28_10, IGARSS 2000, Hawaii.

Irons JR, Markham BL, Nelson RF, Toll DL, Williams DL, Latty RS, Stauffer ML (1985). The effects of spatial resolution on the classification of Thematic Mapper data. International Journal of Remote Sensing, 6(8):1385-403.

Laporterie F, Flouzat G, Amram O (2001). Spatial and temporal satellite data fusion with morphological pyramids for terrestrial surfaces survey. Septembre 2001, $8^{\text {th }}$ International Symposium Remote Sensing, Toulouse, France, SPIE 4541:199-210.

Laporterie F, Flouzat G. The morphological pyramid concept as a tool for multi-resolution data fusion in remote sensing. Integrated Computer-Aided Engineering, on press. 
Lefevre-Fonollosa M-J, Cruchant H (1985). Use of principles of color vision in the processing of remote sensing imagery. Image Science 85 - Helsinki (Finlande). Communication.

Lefevre-Fonollosa M-J, Cruchant H (1986). Application of the principle of visual coding of color to satellite remote sensing images. Third international symposium on optical and optoelectronic applied sciences and engineering -Innsbruck (Autriche).

Lefevre-Fonollosa M-J, Cruchant H (1987). New methods for color digital processing dedicated to actual thematics goals. Riena User's view of remote sensing products-Rome (Italie), Communication.

Lillesand TM, Kiefer RW (1987). Remote Sensing and Image Interpretation. 2nd Ed. New York: John Wiley \& Sons, $721 \mathrm{p}$.

Liu J (2000). Smoothing Filter-based intensity modulation: a spectral preserve image fusion technique for improving spatial details. Int Journ of Remote Sensing 21(18):3461-72.

Liu J, Moore J (1998). Pixel block intensity modulation: adding spatial detail to TM band 6 thermal imagery. Int Journal of Remote Sensing 19(13):2477-91.

Mallat S (1989). A theory for multiresolution signal decomposition: The Wavelet representation. IEEE Transactions on Pattern Analysis and Machine Intelligence 11(7):674-93.

Marr D (1982). Vision . A computational investigation into the human representation and processing of visual information. New-York: Freeman.

Minghelli A, Mangolini M, Petit M, Polidori L (2001). Spatial Resolution improvement of MeRIS images by fusion with TM images. IEEE Trans on geos and Rem Sens 39(7):1533-6.

Mougin E, Lo Seen D, Rambal S, Gaston A, Hiernaux P (1995). A regional Sahelian grassland model to be coupled with multispectral satellite data. II: Toward the control of its simulations by remotely sensed indices. Remote Sens Environ 52:194-206.

Nunez J, Otazu X, Fors O, Prades A (1998a). Fusion and reconstruction of Landsat and SPOT images using wavelets. In: Proceeding Fusion of Earth Data, Sophia Antipolis, 103-8.

Nunez J, Otazu X, Fors O, Prades A, Pala V, Arbiol R (1998b). Data fusion of SPOT and Landsat images using additive multiresollution wavelet decomposition. In: Proceeding EUROPTO conference on Image and Signal Processing for Remote Sensing, 202-12.

Nunez J, Otazu X, Fors O, Prades A, Pala V, Arbiol R (1999a). Multiresolution-based image fusion with additive wavelet decomposition. IEEE trans on Geosc and Rem Sens 37(3):1204-11.

Nunez J, Otazu X, Fors O (1999b). Image fusion with additive multiresolution wavelet decomposition. Applications to SPOT+Landsat images. Journ of the optic Soc of Am A 16(3):467-74.
Paradella W, Bignelli P, Veneziani P, Pietsch R, Toutin T (1997). Airborne and spaceborn synthetic aperture Radar SAR integration with Landsat TM and GammaRay spectrometry data for geological mapping in a tropical rainforest environment, the Carajas Mineral Province, Brazil. International Journal of Remote Sensing 18(7):1483-1501.

Pavel M, Sharma R (1996). Fusion of Radar images rectification without the flat Earth assumption. In: Proceedings of the SPIE, 108-18.

Perry CR, Lautenschlager LF (1984). Functional equivalence of spectral vegetation indices. Remote Sens Environ $14: 169-82$.

Pradines D (1986). Improving Spot images size and multispectral resolution. SPIE Earth Remote Sensing Using the Landsat Thematic Mapper and SPOT sensor systems, 98-102.

Price J (1987). Combining panchromatic and multispectral imagery from dual resolution satellite instruments. Remote Sensing of Environment 21:119-28.

Proenca M, Flouzat G (1991). Ortogonal wavelet analysis: a multiresolution tool applied to remote sensing images. In: Proceedings IGARSS'91, Helsinki, 1463-5.

Proenca M (1992). La transformée en ondelettes appliquée au traitement d'images de télédétection. Thèse en traitement d'images, 1992.

Puyou-Lascassies P, Flouzat G, Gay M, Vignolles C (1994). Validation of multiple linear regression for crop reflectance estimation with coarse resolution remote sensing imagery. Rem Sens of Env 49:155-66.

Quarmby N, Townshend J, Settle J, White K, Milnes M, Hindle T, Silleos N (1992). Linear mixture modeling applied to AVHRR data for crop area estimation. Intern. Journal of Remote Sensing 13:415-25.

Ranchin T (1998). Imporving spatial resolution of spaceborne images using airbone images. In: Proceeding Fusion of earth data, Sophia Antipolis, 37-44.

Ranchin T, Wald L (2000). Fusion of high spatial and spectral resolution images: the ARSIS concept and its implementation. Photogrammetric engineering and remote sensing 66(1):49-61.

Shetselaar E (2001). On preserving spectral balance in image fusion and its advantages for geological image interpretation. Photogrammetric engineering and remote sensing 67(8):925-34.

Scheunders P, De Backer S (2001). Fusion and merging of multispectral images with use of multiscale fundamental forms. Journal of the optical society of America A 18(10):2469-77.

Schowengert R (1980). Reconstruction of multispatial, multispectral image data using spatial frequency content. Photogrammetric engineering and remote sensing 46(10):1325-34.

Sharma R, Pavel M (1996). Adaptative and statistical image fusion. Society for information display XXVII:969-72. 
Tom V (1986). A synergistic approach for multispectral image restoration using reference imagery. In: Proceedings IGARSS'86, 559-64.

Verstraete M, Pinty B (1996). Designing optimal spectral indices for remote sensing applications, IEEE Transactions on Geoscience and Remote Sensing 34:1254-65.

Welch R, Ehlers M (1987). Merging multiresolution SPOT HRV and Landsat TM data. Photogrammetric engineering and remote sensing 53(3):301-3.

Yesou H, Besnus Y, Rolet J (1993). Merging Seasat and SPOT imagery for the study of geologic structures in a temperate agricultural region. Remote Sensing of Environment 43(3):265-79.

Yesou H, Besnus Y, Rolet J (1994). Perception of a geological body using multisources remotely sensed data - relative influence of the spectral content and of the spatial resolution. International Journal of Remote Sensing 15(12):2495-510.

Yocky D (1996). Multiresolution wavelet decomposition image merger of Landsat thematic mapper and SPOT Panchromatic data. Photogrammetric Engin and Remote Sensing 62(9):1067-74.

Zhang Y (1999). A new merging method and its spectral and spatial effects. International Journal of Remote Sensing 20(10):2003-14.

Zhou J, Civco D, Silander J (1998). A wavelet transform method to merge LANDSAT TM and SPOT panchromatic data. International Journal of Remote Sensing 19(4):743-57.

Zhukov B, Oertel D, Lanzl F, Reinhäckel G (1999). Unmixing-based multisensor multiresolution image fusion. IEEE Transactions on geoscience and Remote Sensing 37(3):1212-26. 